\title{
Neonatal Capsaicin Treatment Attenuates Spinal Fos Activation and Dynorphin Gene Expression following Peripheral Tissue Inflammation and Hyperalgesia
}

\author{
J. L. K. Hylden, K. Noguchi, and M. A. Ruda \\ Neurobiology and Anesthesiology Branch, National Institute of Dental Research, National Institutes of Health, Bethesda, \\ Maryland 20892
}

\begin{abstract}
An animal model of nociception involving unilateral hindpaw inflammation has been used to examine behavioral, molecular, and biochemical aspects of well-characterized spinal cord neural circuits involved in pain transmission. The neurotoxin capsaicin administered neonatally was used to modify this neuronal system by producing a selective destruction of most small, unmeylinated primary afferent axons. Capsaicin had minimal effects on the behavioral hyperalgesia and edema associated with the hindpaw inflammation and on the constitutive expression of preprodynorphin (PPD) mRNA and preproenkephalin mRNA in the spinal cord. However, the inflammation-induced increases in Fos-like immunoreactivity (Fos-LI) and in PPD mRNA were greatly attenuated by neonatal capsaicin treatment. The data indicate that input from small-diameter unmyelinated primary afferents is important for the stimulus-induced increase in Fos$L I$ and PPD mRNA. Our finding that neonatal capsaicin reduces the levels of Fos-LI and PPD mRNA in a related fashion in the spinal dorsal horn provides further evidence for a relationship between the protein product of the c-fos protooncogene and regulation of dynorphin gene transcription.
\end{abstract}

Subcutaneous injection of a chemical irritant, complete Freund's adjuvant (CFA), can be used to induce unilateral hindpaw edema and thermal hyperalgesia of prolonged duration (Hargreaves et al., 1988; Iadarola et al., 1988b). This animal model of nociception permits us to make observations relevant to the function of a well-characterized neuronal pathway and to the processes involved in neuronal plasticity in general. More importantly, it offers a unique opportunity to examine the molecular, biochemical, physiological, and behavioral events of nociception. The noxious stimulation resulting from CFA injection has been shown to induce the expression of the protooncogene $c$-fos (Draisci and Iadarola, 1989) as well as expression of Fos or Fos-related proteinlike immunoreactivity (Fos-LI) (Hunt et al., 1987; Menétrey et al., 1989; Presley et al., 1990; Noguchi et al., 1991, 1992). The protein products of protooncogenes such as c-fos appear to function as transcription fac-

\footnotetext{
Received June 21, 1991; revised Nov. 22, 1991; accepted Dec. 4, 1991.

We thank B. Allen and E. Humphrey for their excellent technical support and Dr. A. Steinberg for her contribution to this project during her rotation through our laboratory. We also extend our appreciation to Drs. G. J. Bennett, M. De Leon, R. Dubner, and D. Hammond for critical reading of the manuscript.

Correspondence should be addressed to M. A. Ruda, NAB, NIDR, NIH, 9000 Rockville Pike, Building 30, Room B20, Betnesda, MD 20892.

Copyright (c) 1992 Society for Neuroscience $0270-6474 / 92 / 121716-10 \$ 05.00 / 0$
}

tors that bind to DNA or to DNA-binding proteins to regulate transcription (Curran and Morgan, 1987; Morgan and Curran, 1989; Sheng and Greenberg, 1990). Unilateral hindpaw inflammation also induces an increase in the expression of spinal cord opioid gene mRNAs and the resultant peptides (Iadarola et al., 1988a,b; Millan et al., 1988; Ruda et al., 1988; Noguchi et al., 1989). Neurons with increased levels of preprodynorphin (PPD) mRNA (Ruda et al., 1988; Noguchi et al., 1991) and preproenkephalin (PPE) mRNA (Noguchi et al., 1989, 1992) are located predominantly in laminae I-II and V-VI, as are neurons with Fos-LI. The majority of neurons exhibiting an increase in either PPD or PPE mRNA after inflammation also colocalize Fos-LI (Noguchi et al., 1991a,b). These data suggest that a relationship may exist between the induction of Fos and Fos-related proteins and the subsequent regulation of opioid gene expression in the spinal cord following peripheral stimulation.

Capsaicin is a neurotoxin that, when administered to neonatal rats, results in the destruction of a large subpopulation of smalldiameter, mainly unmyelinated primary afferents. These unmyelinated axons include subpopulations that contain the peptides substance $P$ (SP) and calcitonin gene-related peptide (Skofitsch and Jacobowitz, 1985; Buck and Burks, 1986; Hammond and Ruda, 1989, 1991; Kashiba et al., 1990). We have used neonatal capsaicin treatment as a tool to destroy a population of primary afferents, most of which convey nociceptive inputs to the spinal cord, and have examined the resultant effect on the production of inflammation-induced edema, hyperalgesia, and the induction of Fos protein and PPD mRNA in the spinal cord. Our observations demonstrate that edema and comparable levels of hyperalgesia can be produced in animals that lack the majority of their unmyelinated primary afferent axons. However, the induction of Fos protein and PPD mRNA seen in control animals with inflammation-induced hyperalgesia is greatly attenuated in neonatal capsaicin-treated rats.

\section{Materials and Methods}

Capsaicin treatment. Two-day-old Sprague-Dawley rats of both sexes were obtained from six different litters. Each rat pup received a single subcutaneous injection of capsaicin $(50 \mathrm{mg} / \mathrm{kg}$, Sigma) or vehicle (10: $10: 80 \mathrm{v} / \mathrm{v}$ Tween 80:ethanol : saline) in a volume of $5 \mu \mathrm{l} / \mathrm{gm}$. Care was taken that leakage from the injection site did not occur. Control animals were marked by a small subcutaneous injection of dye that was not visible through the skin after the growth of hair.

Nociceptive testing. From 5 to 8 weeks of age, rats were tested for their response to noxious thermal stimuli. For this purpose, rats were placed on an elevated glass surface under a clear plastic chamber. A radiant heat source was positioned directly under one hindpaw so that the thermal stimulus would be concentrated on the glabrous skin behind 
(proximal to) the pads. Initiation of a trial by turning on the light source also activated a timer. The timer and heat source were automatically turned off when a change in reflected light was detected by a photocel (Hargreaves et al., 1988). An upper cutoff latency of $20 \mathrm{sec}$ was imposed to prevent tissue damage. Control rats with noninflamed paws have been shown to withdraw their paws at a temperature of approximately $45^{\circ} \mathrm{C}$, whereas inflamed paws were withdrawn at about $39^{\circ} \mathrm{C}$ (Hargreaves et al., 1988). The paw withdrawal latency was recorded to the nearest $0.1 \mathrm{sec}$. Testing was repeated for each paw at greater than $2 \mathrm{~min}$ intervals. The mean of two trials was used for subsequent analysis. Behavioral data were obtained from 36 rats (12 vehicle treated and 24 capsaicin treated).

Variability in the literature with respect to the hypoalgesic effect of capsaicin treatment may depend on both the nature of the nociceptive test, the age of the animal at the time of treatment, and the length of time between treatment and testing (Hammond and Ruda, 1991). We have tested our animals at a time when the capsaicin effects on thermal responses are maximal (5-8 weeks) and have used a slowly rising thermal pulse as a stimulus. The withdrawal latency in this paradigm can be correlated to nociceptive detection threshold. Our testing method differs from that described by Doucette et al. (1987), who used a hot probe at superthreshold temperature $\left(65-70^{\circ} \mathrm{C}\right)$ applied to the glabrous skin of the paws of capsaicin-treated and control rats. Our testing procedure has given reliable and reproducible results and has proven to be an easily quantifiable method for assessing unilateral hyperalgesia, a condition that is typically characterized by more integrative responses such as limb guarding, hyperreflexia, and paw licking.

Induction of hindpaw inflammation and behavioral testing. All rats were given a subcutaneous injection of $0.2 \mathrm{ml}$ of complete Freund's adjuvant (CFA; Mycobacterium tuberculosis; Sigma) suspended in an oil : saline $(1: 1)$ emulsion (at a concentration of $0.5 \mathrm{mg}$ of Mycobacterium $/ \mathrm{ml}$ of emulsion) into the plantar surface of one hindpaw at 8 weeks of age. CFA injection into the hindpaw produces localized inflammation, as characterized by erythema, edema, and hyperalgesia, that peaks at 6-24 hr after injection and lasts more than $5 \mathrm{~d}$ (Iadarola et al., 1988a Hylden et al., 1989). Thermal nociceptive testing using the methods described above was repeated in groups of rats at $2,6,24$, and $48 \mathrm{hr}$. Edema was estimated by measuring dorsal-plantar paw diameter with a vernier caliper. Rats with unilateral hindpaw inflammation demonstrate normal eating and grooming behavior and normal levels of locomotor activity (Iadarola ct al., 1988a) but tend to guard the inflamed paw. In order to minimize any discomfort, rats were housed in cages containing soft sawdust bedding and the number of animals used was kept to a minimum. This model of unilateral inflammation has been approved by the National Institute of Dental Research Animal Care and Use Committee and conforms to the guidelines of the International Association for the Study of Pain (Zimmermann, 1983).

Paw withdrawal latency and paw diameter data were combined for all litters tested. Significant main effects were determined by analysis of variance. A $p$ value of less than 0.05 was taken to indicate significance. The investigator was blind with respect to treatment group during behavioral testing.

Immunocytochemistry. Representative rats from each treatment group were deeply anesthetized immediately after behavioral testing at each time point (four to six rats at $2,6,24$, and $48 \mathrm{hr}$ ) and perfused through the heart with $4 \%$ paraformaldehyde in $0.1 \mathrm{M}$ phosphate buffer ( $\mathrm{pH} 7.4$ ). Spinal cords were removed, postfixed overnight in cold fixative, and subsequently stored in cold phosphate-buffered saline (PBS). Following cryoprotection in $30 \%$ sucrose, $24 \mu \mathrm{m}$ transverse sections were cut from the lumbar enlargement on a cryostat. Tissue sections from the LA lumbar segment were used for analysis of Fos-immunoreactive nuclei. Sections from other lumbar segments were used for analysis of SPimmunoreactive fibers. Tissue sections from capsaicin- and vehicletreated littermates were processed simultaneously under identical conditions.

Immunocytochemical staining was done using the peroxidase-antiperoxidase (PAP) method (Sternberger, 1979) as previously described by Ruda et al. (1982). Tissue sections were incubated in polyclonal antiserum to Fos and Fos-related proteins (1:250; generously provided by Dr. M. J. Iadarola; Iadarola et al., 1989) or SP (1:7000; Incstar) for $48 \mathrm{hr}$ at $4^{\circ} \mathrm{C}$ with gentle agitation, followed by incubation in secondary antiserum (goat anti-rabbit IgG, 1:200; Accurate) for $60 \mathrm{~min}$ at room temperature. Following incubation in rabbit PAP $(1: 3000,60 \mathrm{~min}$ at room temperature), the sections were rinsed in two changes of PBS and reacted with $0.05 \% 3,3^{\prime}$-diaminobenzidine tetrahydrochloride in the presence of $0.01 \%$ hydrogen peroxide $(6-12 \mathrm{~min})$. Tissue sections were then washed in PBS, mounted on slides, dried, and coverslipped. The epitope recognized by the Fos antibody is from the conserved region of the protein and is present in Fra-1, Fra-2, and Fos B as well as Fos (Iadarola et al., 1989). Therefore, the antibody may have recognized these other proteins that may also be involved in gene transcription. Fos-LI observed in these experiments has therefore been referred to as indicating the presence of Fos or Fos-related proteins. Tissue sections from the same animals that were used for determination of Fos-LI were examined for the degree of SP staining

Neurons with Fos-LI in their nuclei ipsilateral and contralateral to inflamed hindpaws were counted in randomly selected tissue sections $(N=2-3$ rats per treatment group at each time point, 10-20 sections per rat). Pairwise comparison ( $t$ test) was used to determine ipsilateral versus contralateral differences in each animal. An analysis of variance compared the number of Fos-like immunoreactive nuclei ipsilateral to the inflamed hindpaw (mean number of nuclei per section in each animal) in the capsaicin-treated versus the vehicle-treated groups at 2,6 , 24 , and 48 hr. $p<0.05$ was considered signiticantly different.

In situ hybridization. For in situ hybridization histochemistry, tissue sections from rats $4 \mathrm{~d}$ after unilateral CFA hindpaw injection were used. Transverse $21 \mu \mathrm{m}$ sections from the $\mathrm{L} 4$ segment were cut with a cryostat, thaw mounted onto Vectabond (Vector Lab. Inc.)-coated slides, and stored at $-80^{\circ} \mathrm{C}$ until ready to use.

To begin the in situ hybridization, tissue sections were digested with proteinase $\mathrm{K}\left(1 \mathrm{mg} / \mathrm{ml}, 37^{\circ} \mathrm{C}\right.$, for $30 \mathrm{~min}$; Sigma $)$ in $0.1 \mathrm{M}$ Tris, $0.05 \mathrm{M}$ cthylencdiaminetetra-acetic acid ( $\mathrm{pH} 8.0)$; rinsed briefly in distilled water; followed by $0.1 \mathrm{M}$ triethanolamine (TEA) (pH 8.0); acetylated with $0.25 \%$ acetic anhydrate in $0.1 \mathrm{M}$ TEA ( $\mathrm{pH} 8.0$ ); and dehydrated through graded ethanols. The hybridization was performed overnight at $37^{\circ} \mathrm{C}$ with $10^{6} \mathrm{dpm}$ of labeled probe $/ 100 \mu \mathrm{l}$ buffer/slide. The buffer contained $4 \times$ saline-sodium citrate $(\mathrm{SSC} ; 1 \times \mathrm{SSC}=0.15 \mathrm{mM} \mathrm{NaCl}, 0.015 \mathrm{~mm}$ sodium citrate), $50 \%$ formamide, $0.12 \mathrm{M}$ phosphate buffer; $1 \times$ Denhardt's solution, $0.2 \%$ sodium dodecyl sulfate, $250 \mathrm{mg} / \mathrm{ml}$ yeast $t$ RNA, $10 \%$ dextran sulfate, and $100 \mathrm{~mm}$ dithiothreitol. The oligonucleotide probes (Synthecell Corp.) consisted of 48 bases complementary to either bases 862-909 of the PPD mRNA sequence (Civelli et al., 1985) or bases 512-559 of the PPE mRNA sequence (Yoshikawa et al., 1984). The purified probes were labeled with ${ }^{35} \mathrm{~S}$-deoxyadenosine $[\alpha$-thio] triphosphate (New England Nuclear) to a specific activity of 5-10 $\times 10^{3}$ $\mathrm{Ci} / \mathrm{mmol}$. Following hybridization, the sections were washed four times for $15 \mathrm{~min}$ each at $55^{\circ} \mathrm{C}$ in $1 \times \mathrm{SSC}$, followed by a wash in $1 \times \mathrm{SSC}$ at room temperature for $30 \mathrm{~min}$, rinsed in distilled water briefly, and dried. The specificity of the probes and hybridization reaction were verified as described previously (Young et al., 1986; Ruda et al., 1988: Draisci and Iadarola, 1989; Noguchi et al., 1992). In addition, RNA blot analysis of spinal cord tissue using the oligonucleotide probes yielded a single band at the appropriate molecular weight.

For autoradiography, the tissue sections were coated with Kodak NTB3 emulsion (diluted 1:1 with distilled water at $40^{\circ} \mathrm{C}$ ) and exposed for 2-6 weeks in light-tight boxes at $4^{\circ} \mathrm{C}$. After development in D19 (Kodak) and fixing in $24 \%$ sodium thiosulfate, the sections were rinsed in distilled water, stained with neutral red, and coverslipped. We quantified the change of PPD mRNA by counting all labeled cells on 12 tissue sections taken from the $\mathrm{L} 5 \mathrm{lcvcl}$ of two control and two capsaicintreated rats. The total number of PPD mRNA-positive neurons in superficial or deep dorsal horn laminae was recorded on the sides ipsilateral and contralateral to the inflammation. To facilitate the quantification, neurons with grain densities at 10 times higher than background were considered positively labeled for PPD mRNA. Since our background labeling was low (1.8 grains $/ 10 \mathrm{~mm}^{2}$ ), this high signal-tonoise ratio effectively eliminated from our counts dorsal horn neurons with low constitutive levels of expression especially on the side contralateral to the inflammation, and emphasized the number of neurons that had increased levels of PPD mRNA expression.

\section{Results}

Edema and hyperalgesia in capsaicin- and vehicle-treated rats Behavioral responsitivity to nociceptive stimulation was tested between 5 and 8 weeks of age using a noxious thermal stimulus applied to the plantar surface of noninflamed hindpaws of capsaicin- and vehicle-treated rats. Capsaicin-treated rats responded to the noxious thermal stimulus although they exhibited 


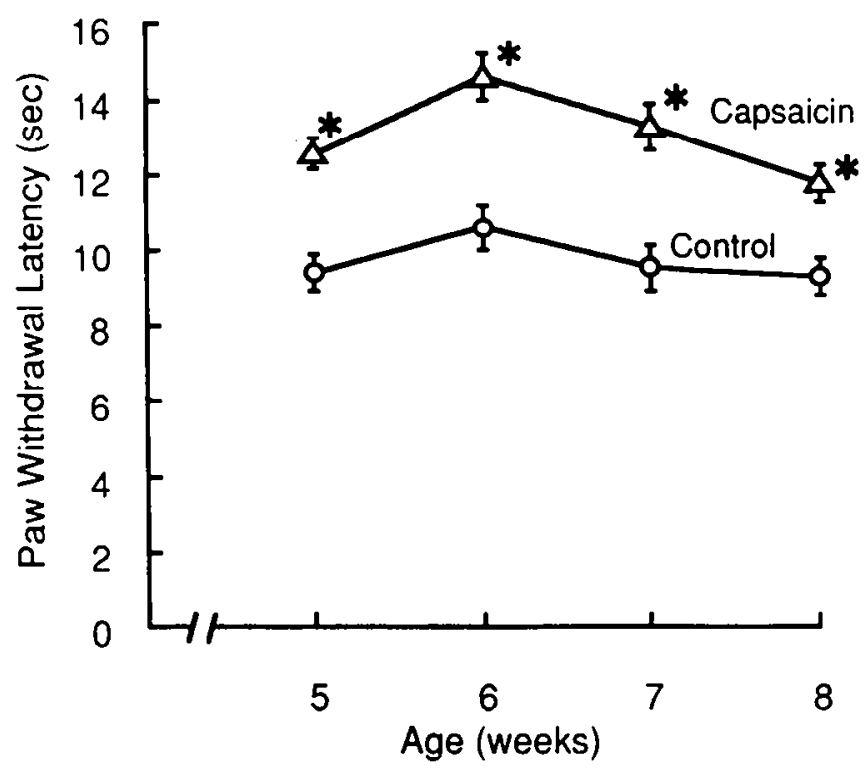

Figure 1. Paw withdrawal latency of control and capsaicin-treated rats at 5-8 weeks of age. Data are from six litters treated at postnatal day 2 with capsaicin' ( $N=24$ rats; triangles) or vehicle ( $N=12$ rats; circles).

*, Capsaicin-treated rats had significantly elevated withdrawal latencies over this 5-8 week time course $(p<0.001$, ANOVA). Error bars represent 1 SEM.

significantly longer paw withdrawal latencies than did their vehicle-treated littermates (Fig. 1). Between 5 and 8 weeks of age, capsaicin-treated rats had weekly average paw withdrawal latencies of 11.6 to $14.5 \mathrm{sec}$ while control rats had average paw withdrawal latencies of 9.2-10.4 sec at 5-8 weeks.

At 8 weeks of age, edema was produced by unilateral injection of CFA into one hindpaw of both capsaicin- and vehicle-treated rats. The time course of the development of the edema and its resolution was the same in capsaicin-treated and control rats,

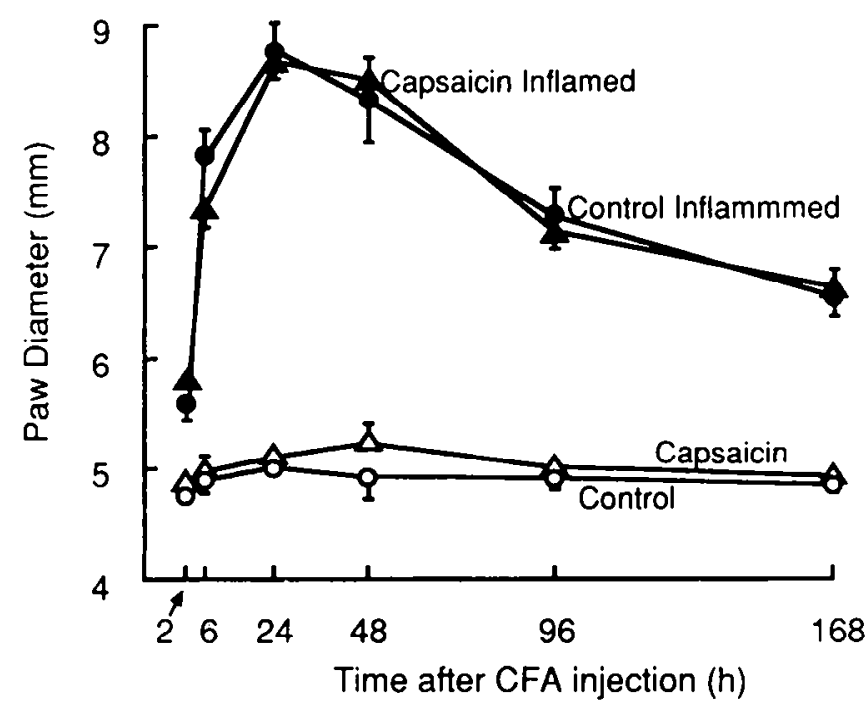

Figure 2. Dorsal-plantar paw diameter at $2 \mathrm{hr}$ to $7 \mathrm{~d}$ after injection of CFA in one hindpaw of control $(N=8$; circles $)$ and capsaicin-treated rats $(N=14$; triangles). Data obtained from inflamed paws are represented by solid symbols, and from contralateral noninflamed paws, by open symbols. There was no effect of capsaicin treatment on CFAinduced cdema over this time course (ANOVA). Error bars represent 1 SEM.

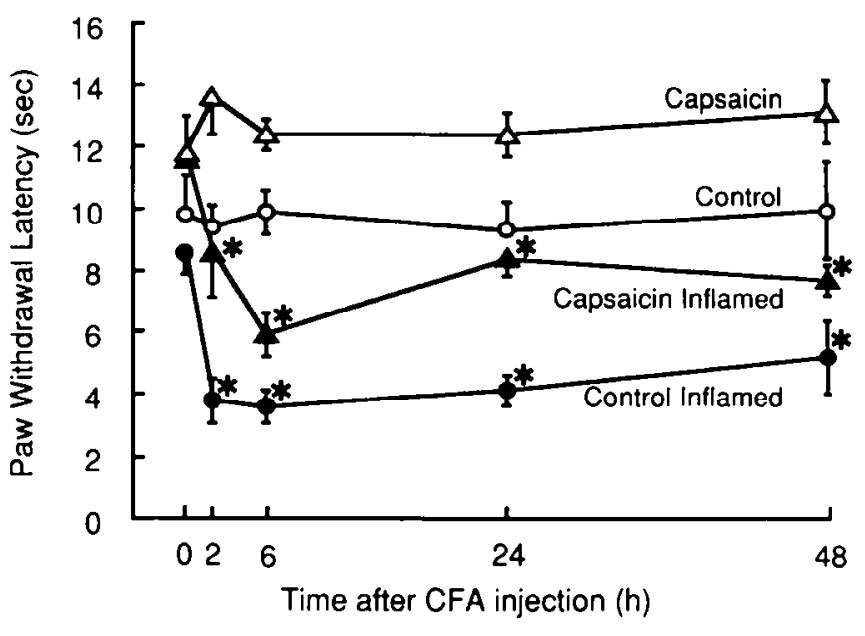

Figure 3. Paw withdrawal latency before and $2-48 \mathrm{hr}$ after injection of CFA in one hindpaw of control $(N=12)$ and capsaicin-treated rats $(N=24) . *$, Inflamed paw withdrawal latencies were significantly lower $(p<0.01$, ANOVA) than contralateral noninflamed paw withdrawal latencies at $2-48 \mathrm{hr}$ for both control (solid circles) and capsaicin-treated rats (solid triangles). The time course and magnitude of the decrease in latency were not different in the two treatment groups. Contralateral noninflamed paws in control (open circles) and capsaicin-treated rats (open triangles) showed no change in paw withdrawal latency. Error bars represent 1 SEM.

as measured by paw diameter $2 \mathrm{hr}$ to $7 \mathrm{~d}$ after injection of CFA (Fig. 2). The peak response occurred at $24 \mathrm{hr}$. The injected hindpaw also became hyperalgesic in both capsaicin- and vehicle-treated rats (Fig. 3). Inflammation was accompanied by a rapid decrease in paw withdrawal latency that was maximal at $6 \mathrm{hr}$ after CFA injection in both treatment groups (Fig. 3). In capsaicin-treated rats, inflamed paws had a baseline average value of $11.8 \mathrm{sec}$ and a low of $5.9 \mathrm{sec}$ at $6 \mathrm{hr}$ (net decrease, 5.9 sec). Paw withdrawal latencies were still significantly decreased in both treatment groups at 24 and $48 \mathrm{hr}$. The net decrease in withdrawal latency of the inflamed paw in capsaicin-treated rats was $5.9 \mathrm{sec}$, whereas the net decrease in withdrawal latency of the inflamed paw in the vehicle-treated rats was $5.0 \mathrm{sec}$. When the latency data from inflamed hindpaws were analyzed using ANOVA, the treatment versus time interaction term was found not to be significant. Thus, the time course and magnitude of hyperalgesia were similar for capsaicin-treated and control animals. Contralateral noninflamed hindpaws showed no change in withdrawal latency in either group.

\section{Distribution of Fos-like immunoreactive nuclei}

The Fos-LI in spinal cord neurons was restricted to the cell nucleus (Fig. 4). In capsaicin-treated rats, a slight increase in the number of labeled nuclei was detected ipsilateral to the inflamed hindpaw in laminae I and II at all time points studied as compared to the contralateral noninflamed hindpaw. However, the difference was only statistically significant at $6 \mathrm{hr}$ (see Fig. 6). The labeled nuclei were concentrated in the medial twothirds of the superficial laminae, a region of the L4 segment that received direct input from the inflamed hindlimb (Fig. 5). The deeper laminae had few nuclei exhibiting induction of Fos-LI, and the ipsilateral versus contralateral difference in labeled nuclei was statistically significant only at the $48 \mathrm{hr}$ time point (Fig. 6).

By contrast, in vehicle-treated rats, the unilateral hindpaw 

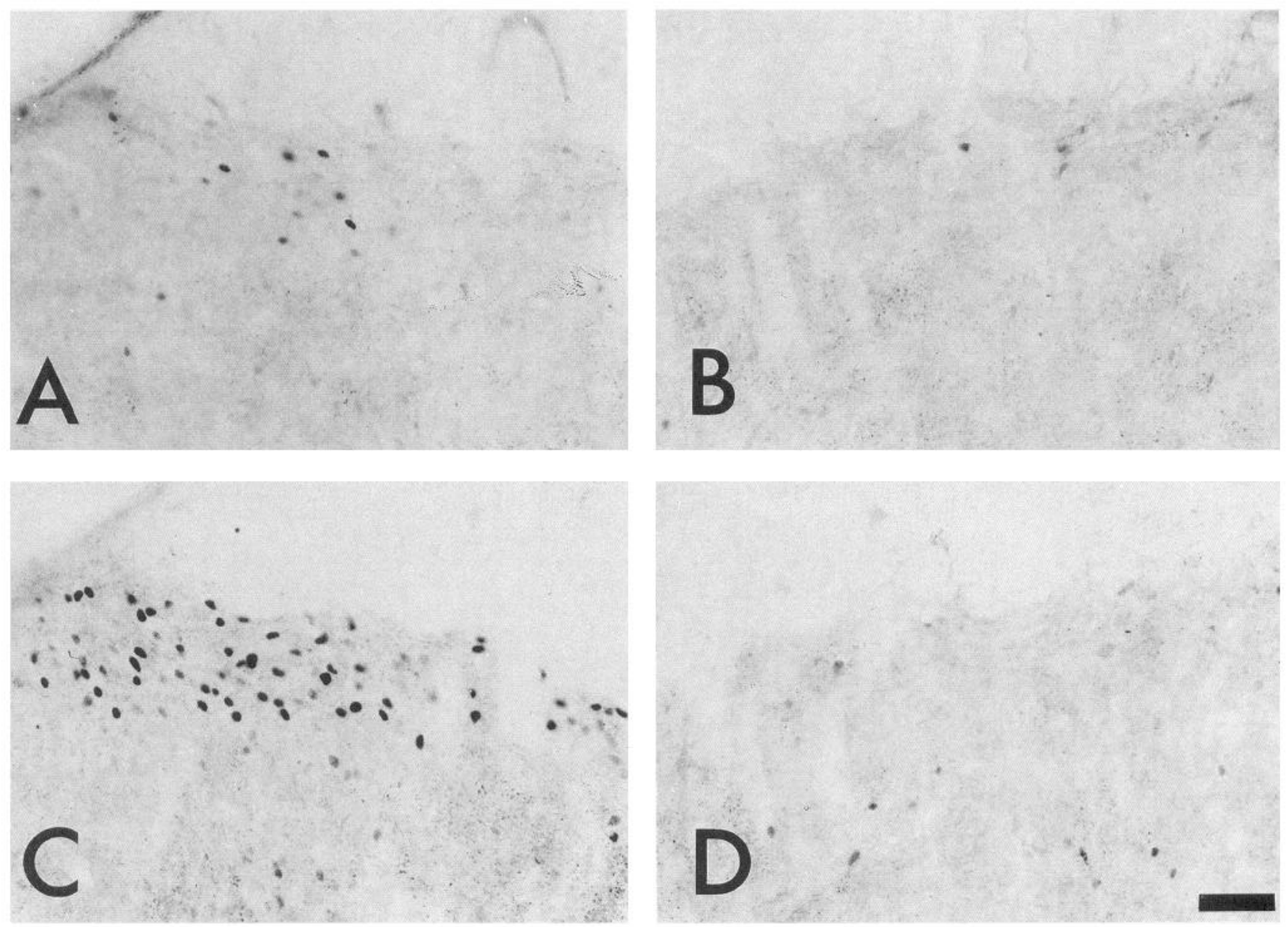

Figure 4. Photomicrographs of transverse tissue sections from the L4 lumbar segment of a capsaicin-treated rat $(A$ and $B)$ and a control rat $(C$ and $D$ ) that were stained for Fos-LI. These sections were obtained from rats that were perfused at $6 \mathrm{hr}$ after unilateral injection of CFA. The superficial dorsal horn ipsilateral to inflammation is shown in $A$ and $C$ and contralateral to inflammation is shown in $B$ and $D$. Note the abundance of Fos-labeled nuclei in laminae I and II just under and medial to the dorsal root entry zone ipsilateral to inflammation in the section from the control rat $(C)$ and attenuation of the number of Fos-LI nuclei in the capsaicin-treated rat $(A)$. Scale bar, $50 \mu \mathrm{m}$.

inflammation produced a dramatic induction of Fos-LI in the dorsal horn on the injected side as compared to the contralateral side (Fig. 4). In the superficial laminae, the increase in labeled nuclei on the inflamed side was statistically significant at all time points studied and was maximal at $6 \mathrm{hr}$ (Fig. 6). In the deeper laminae, there was a statistically significant increase at all time points but the peak effect was delayed compared to the superficial laminae, occurring at $24 \mathrm{hr}$. Thus, capsaicin treatment appeared to decrease induction of Fos-LI markedly and only transient significant increases were seen at isolated time points. Few labeled nuclei were found in the spinal dorsal horn contralateral to the inflammation in both capsaicin-treated and vehicle-treated rats (Fig. 6).

\section{Distribution of PPD neurons}

In neonatal capsaicin-treated rats, in situ hybridization revealed a few neurons in the superficial laminae and neck of the dorsal horn ipsilateral to the inflammation with increased PPD mRNA (Fig. $7 A$ ) compared to the low constitutive expression on the contralateral side (Fig. 7B). However, there were fewer cells with a detectible upregulation of PPD mRNA than that observed in vehicle-treated animals with an inflamed hindpaw (Fig. 7C).
Although there was variability in the number of neurons with high levels of PPD mRNA expression in individual sections, the superficial dorsal horn laminae in capsaicin-treated rats overall had an $82 \%$ reduction in the number of labeled neurons compared to vehicle-treated rats (Table 1). In the deep dorsal horn laminae of capsaicin-treated rats, there was a $50 \%$ reduction in neurons that exhibited increased PPD mRNA compared to vehicle-treated rats (Table 1).

Table 1. Effect of neonatal capsaicin treatment on activation of PPD mRNA in the spinal cord in a rat model of inflammation and hyperalgesia

\begin{tabular}{lcllll} 
& \multicolumn{2}{l}{$\begin{array}{l}\text { Superficial } \\
\text { dorsal horn }\end{array}$} & & \multicolumn{2}{l}{$\begin{array}{l}\text { Deep } \\
\text { dorsal horn }\end{array}$} \\
\cline { 2 - 3 } \cline { 5 - 6 } \cline { 5 - 6 } & Ipsilateral & $\begin{array}{l}\text { Contra- } \\
\text { lateral }\end{array}$ & & Ipsilateral & $\begin{array}{l}\text { Contra- } \\
\text { lateral }\end{array}$ \\
\hline Capsaicin & 26 & 0 & & 25 & 0 \\
Control & 142 & 3 & & 49 & 2
\end{tabular}

Numbers represent the total number of PPD mRNA-labeled neurons with a signalto-noise ratio of $>10$ from 12 sections of two capsaicin-treated or two control rats at $3 \mathrm{~d}$ after induction of inflammation. 


\section{CAPSAICIN-INFLAMED CONTROL-INFLAMED}

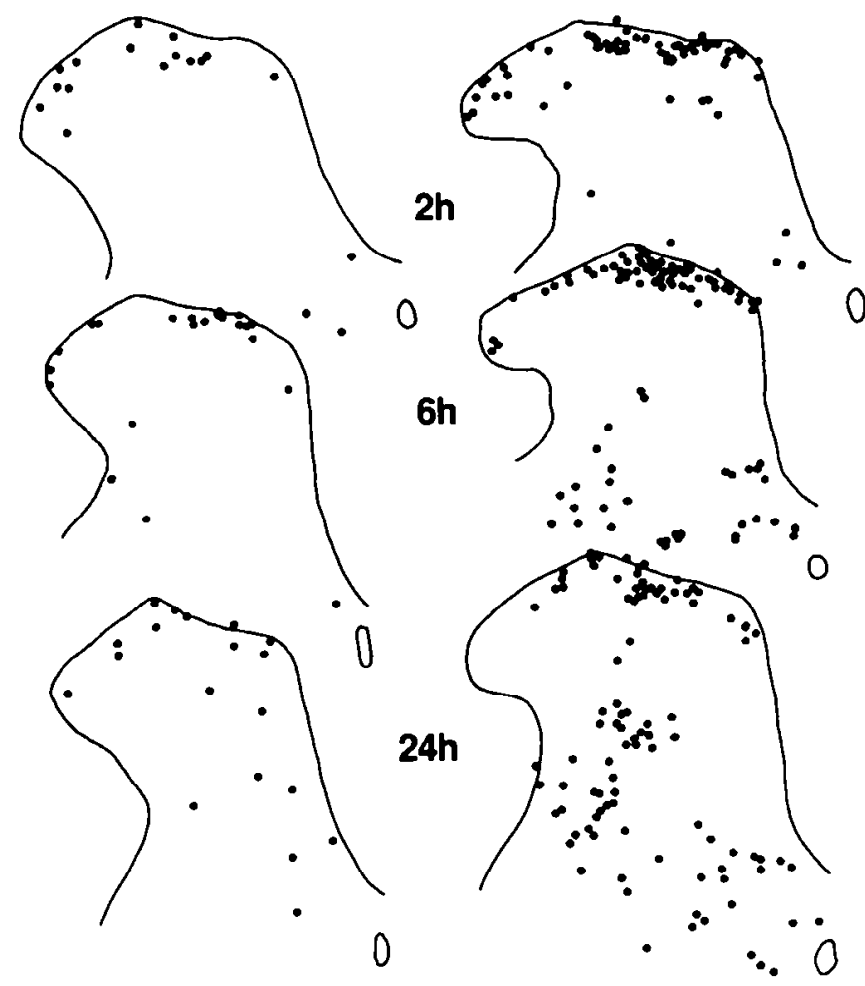

Figure 5. Camera lucida reconstructions of tissue sections through the L4 lumbar spinal cord of capsaicin-treated and control rats illustrating the distribution of Fos-LI nuclei ipsilateral to an inflamed hindpaw at 2,6 , and $24 \mathrm{hr}$ after CFA injection. Each drawing represents the nuclei observed in one $24 \mu \mathrm{m}$ section (each dot represents one labeled nucleus).

\section{Distribution of PPE neurons}

PPE mRNA expression was used to determine whether neonatal capsaicin treatment would result in a generalized alteration in spinal cord gene expression. Eight-week-old rats, neonatally treated with capsaicin, displayed a high level of constitutive PPE mRNA expression in the spinal cord (Fig. 8A). Labeled neurons were found in all laminae of the dorsal horn as well as the ventral horn excluding motoneurons. Taking into account scction-to-section variability in labeling due to the individual components of the neuropil, in situ hybridization suggests that there was no significant difference in labeling of PPE $\mathrm{mRNA}$ in control and neonatal capsaicin-treated rats (compare Fig. 8A,B). Since previous studies in our laboratory have shown only a small effect of inflammation-induced hyperalgesia on PPE mRNA expression, we did not analyze spinal cord sections for changes in PPE mRNA in capsaicin-treated animals with an inflamed hindpaw.

\section{$S P$ immunoreactivity in capsaicin- and vehicle-treated rats}

As a control for the efficacy of capsaicin treatment, tissue sections were examined for SP labeling. Although SP in the dorsal horn may originate from either primary afferent axons, intrinsic dorsal horn neurons, or axons descending from neurons in the brainstem, a major component is C-fiber primary afferents. All capsaicin-treated rats had significant decreases in SP immunoreactivity in both the superficial laminae and the neck of the dorsal horn, areas in which small-diameter primary afferents terminate (Fig. 9). Our observations agree with the reported
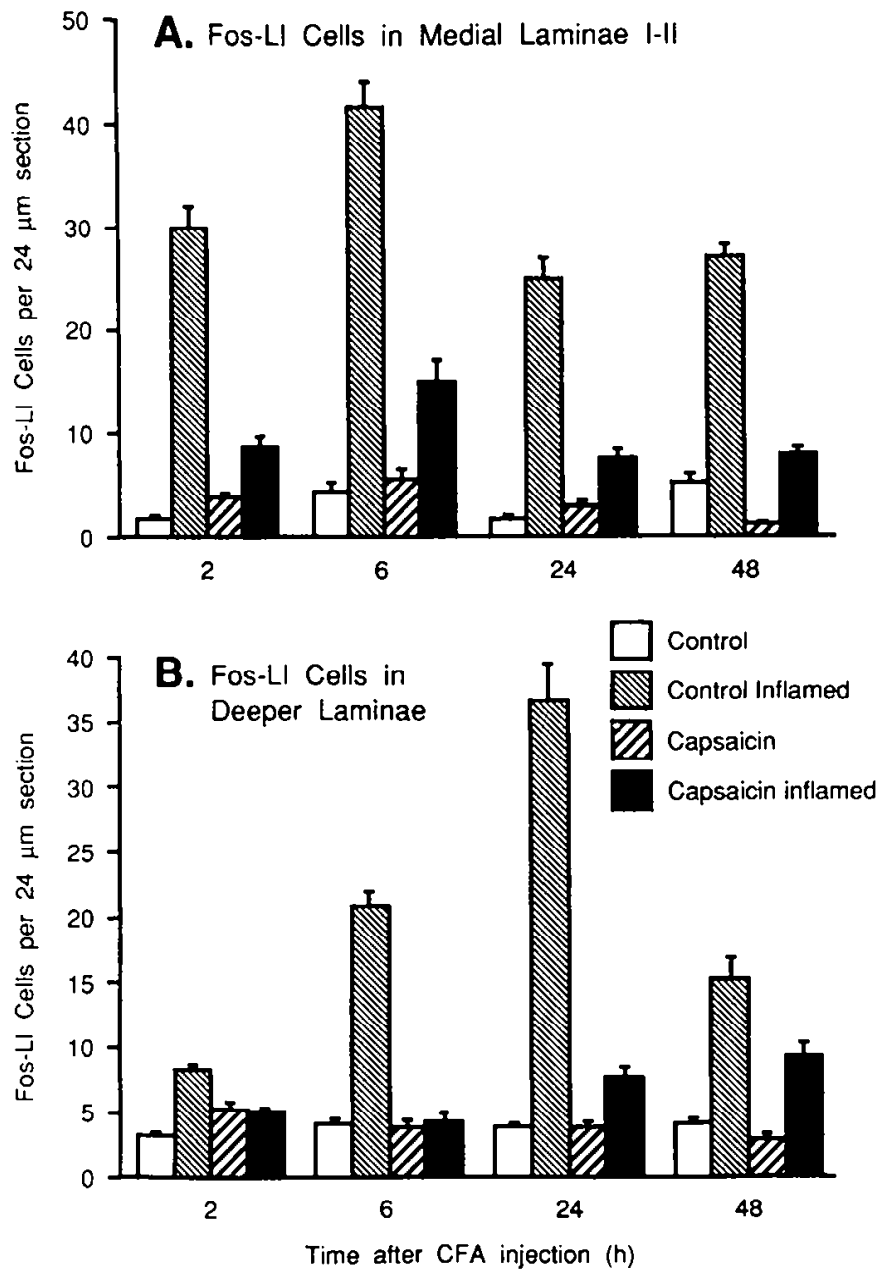

Figure 6. Number of Fos-LI nuclei (mean per section) observed in superficial and deep laminae at $2-48 \mathrm{hr}$ after injection of CFA in one hindpaw. $A$, Nuclei with Fos-LI were counted in the medial two-thirds of laminae I and II of randomly selected $24 \mu \mathrm{m}$ transverse sections from control rats and capsaicin-treated rats $(N=2$ or 3 rats per treatment group at each time point, 10-20 sections were counted per rat). ANOVA comparing the two groups across time indicated a significant attenuation of Fos-LI ipsilateral to inflammation in the superficial laminae in the capsaicin-treated group $(p<0.001)$. Each control animal demonstrated a significant inflamed versus noninflamed difference at all time points $(p<0.05)$. Each capsaicin-treated rat only showed a significant increase in Fos labeling in the superficial laminac at $6 \mathrm{hr}(p<0.05) . B$, Fos-like immunoreactive nuclei were also counted in laminae IV-VII and X of the same tissue sections included in $A$. Capsaicin treat ment significantly attenuated Fos-LI ipsilateral to the inflammation in the deeper laminae $(p<0.001)$. Significant inflamed versus noninflamed differences $(p<$ 0.01 ) occurred at all time points in each vehicle-treated animal, but only at $48 \mathrm{hr}$ for each capsaicin-treated animal. CFA injection had no significant effect on the number of Fos-labeled nuclei observed contralateral to inflammation. Error bars represent 1 SEM.

effects of capsaicin on this neuropeptide at 8 weeks after neonatal capsaicin treatment (Hammond and Ruda 1989, 1991).

\section{Discussion}

Neonatal capsaicin treatment in rats was used to destroy most of the unmyelinated axons in peripheral nerves in order to evaluate the role of such afferents in behavioral hyperalgesia and in the expression of Fos-LI and dynorphin gene expression following peripheral tissue inflammation. We found that both the induction of Fos-LI and the enhanced expression of PPD mRNA 

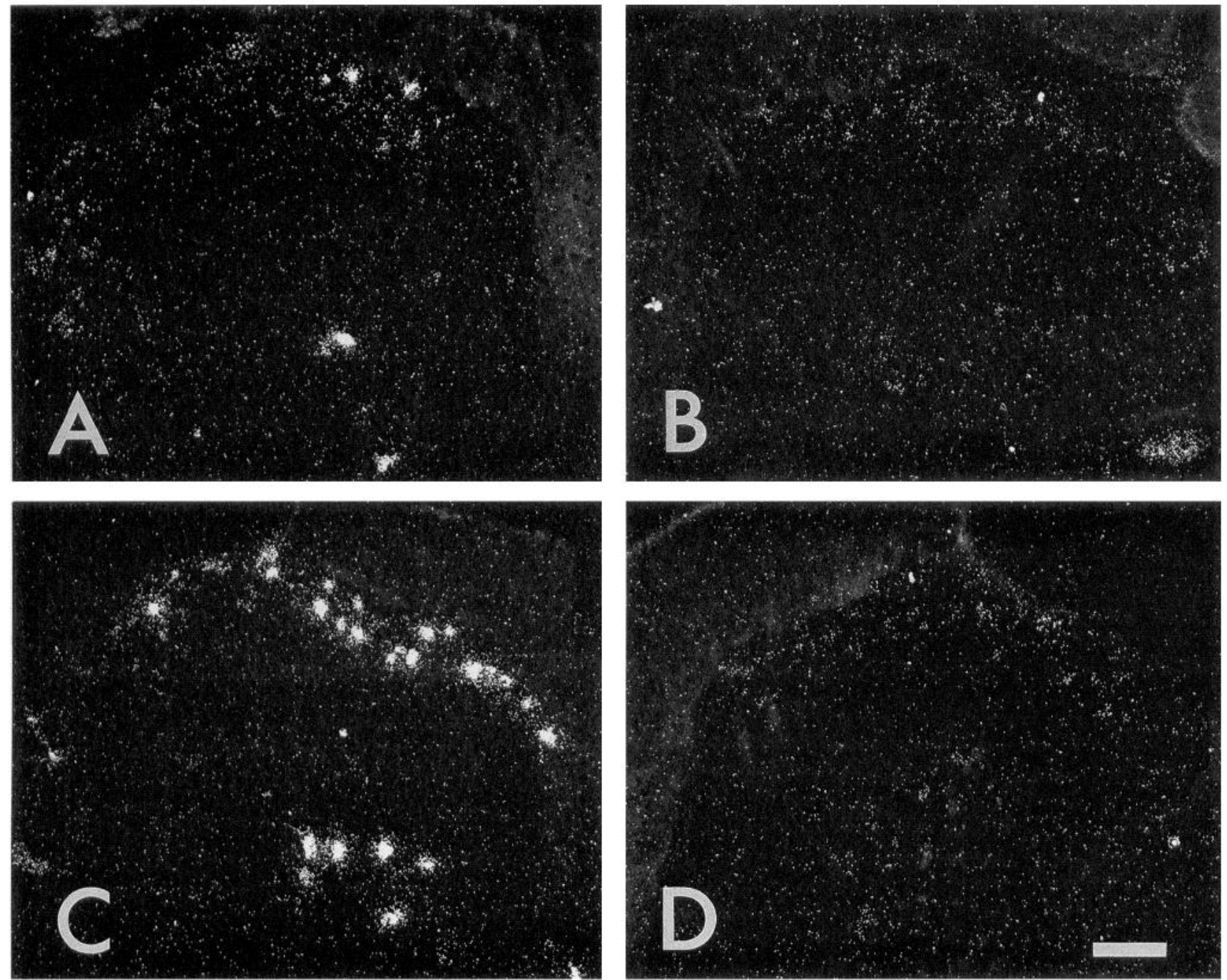

Figure 7. Dark-field photomicrographs of sections of the L5 dorsal horn of neonatal capsaicin-treated $(A$ and $B)$ and control rats $(C$ and $D)$ following in situ hybridization with an ${ }^{35}$ S-labeled PPD probe. At $4 \mathrm{~d}$ after inflammation, the sides ipsilateral to the inflammation $(A$ and $C$ ) exhibit an increased density of silver grains overlying neurons in the superficial and deep laminae as compared to each treatment groups' side contralateral to the inflammation. However, the neuronal response is greatly attenuated in the capsaicin-treated rats $(A)$ as compared to controls $(C)$. Scale bar, $100 \mu \mathrm{m}$.

following inflammation appear to depend to a large extent on input from capsaicin-sensitive primary afferents. We conclude that increased activity of capsaicin-sensitive unmyelinated nociceptive afferents induced by the inflammatory agent CFA is primarily responsible for activation of the cellular immediateearly gene c-fos and the resultant effect of its protein product on target genes. Our finding that neonatal capsaicin treatment reduced the level of Fos-LI and PPD mRNA in a related fashion in the spinal dorsal horn further suggests that the protein product of the c-fos proto-oncogene may be involved in the regulation of dynorphin gene transcription.

It was important to demonstrate that capsaicin-treated and vehicle-treated rats developed similar signs of inflammation in the periphery in order to compare central changes in each group of animals. Capsaicin-treated rats were tested from 5 to 8 weeks of age to verify that the animals detected thermal stimuli and that their sensitivity to thermal stimuli was similar over this time period. The longer paw withdrawal latencies in capsaicintreated than in control rats confirmed previous findings that neonatal capsaicin results in a reduction in thermal sensitivity but does not abolish the response to noxious thermal stimuli (Hammond and Ruda, 1989, 1991). The neurotoxic effect of neonatal capsaicin treatment, however, had a minimal effect on CFA-induced edema and thermal hyperalgesia. The injection of CFA produced similar levels of edema, and the time course and relative magnitude of hyperalgesia were similar in capsaicin-treated and vehicle-treated rats. Capsaicin treatment has long been known to block neurogenic inflammation (Jansco et al., 1977), although the direct action of peptides to produce plasma extravasation is not impaired (Gamse et al., 1980). Thus, the peripheral inflammatory response to CFA injection does not appear to require capsaicin-sensitive neurogenic mechanisms.

We utilized changes in SP levels in the spinal cord to verify that neonatal capsaicin treatment had destroyed a subpopulation of unmyelinated primary afferents in the groups of rats used in this study. Tissue sections immunocytochemically stained for SP showed markedly decreased levels of this peptide at 8 weeks, consistent with its loss from primary afferents, but not from 

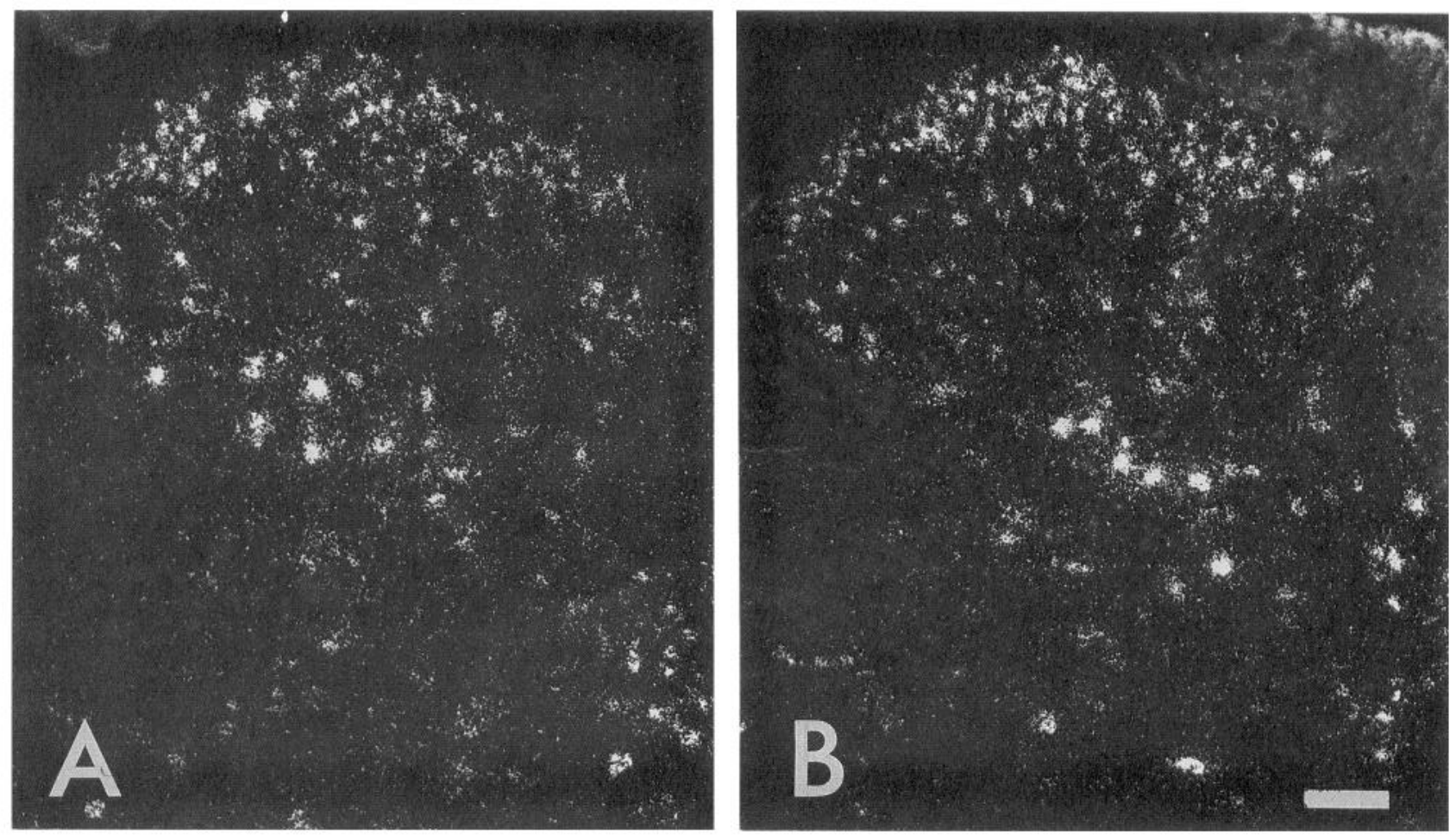

Figure 8. Dark-field photomicrographs of sections of the L5 dorsal horn of neonatal capsaicin-treated $(A)$ and control $(B)$ rats following in situ hybridization with an ${ }^{35} \mathrm{~S}$-labeled synthetic oligonucleotide probe complementary to PPE. Constitutive PPE expression continues at a high level after the capsaicin-induced loss of small-diameter primary afferent input to the spinal cord. Scale bar, $100 \mu \mathrm{m}$.

intrinsic dorsal horn neurons or supraspinal descending axons (Ruda et al., 1986; Solodkin and Ruda, 1988). This finding, in conjunction with the reduced thermal sensitivity of the rats at j-8 weeks, provides evidence that the neonatal capsaicin treatment destroyed a large subpopulation of unmyelinated C-afferents, as previously reported (Nagy et al., 1981). Other studies in our laboratory have confirmed at the electron microscopic level a greater than $85 \%$ decrease in unmyelinated axons in the L5 dorsal roots of 8-week-old neonatal capsaicin-treated rats (M. A. Ruda, unpublished observations). Since myelinated afferents are relatively heat insensitive in the rat (Lynn and Shakhanbeh, 1988), it is possible that the small number of unmyelinated primary afferent fibers that remain after capsaicin treatment are responsible for the observed thermal hyperalgesia.

Neonatal capsaicin treatment may result in changes in the dorsal horn related to the loss of unmyelinated afferents. Such central changes may involve functional deficits or actual cell death of some spinal neurons (Saporta, 1986), altered excitability of spinal neurons (Wall et al., 1982; Cervero et al., 1984), or other compensatory changes (Nagy and Hunt, 1983; Réthelyi et al., 1986). Although such changes did not appear to have an effect on the behavioral response of the animals to inflammation, it is possible that gene expression in the dorsal horn may have been altered. To address this issue, we examined Fos-LI and opioid gene expression under control conditions (no inflammation or noxious peripheral stimulation). Neonatal capsaicin treatment had no effect on the low constitutive expression of Fos-LI or PPD mRNA, or the high constitutive expression of PPE mRNA in the spinal cord. These data indicated that the capsaicin-induced loss of primary afferent axons in the spinal cord did not, of itself, alter the constitutive c-fos or opioid gene expression.
Several studies have demonstrated Fos activation in the spinal cord following noxious peripheral stimulation (Hunt et al., 1987; Bullitt, 1989, 1990; Menétrey et al., 1989; Presley et al., 1990; Tolle et al., 1990; Wisden et al., 1990; Noguchi et al., 1991, 1992). The time course of Fos upregulation appears to depend on the nature of the stimulus (noxious chemical, heat, mechanical) and its duration. Our data from control rats agree with reports that a noxious stimulus produces a rapid increase in Fos-LI in the superficial dorsal horn (Hunt et al., 1987; Menétrey et al., 1989; Presley et al., 1990; Tolle et al., 1990; Williams et al., 1990; Wisden et al., 1990), followed by a delayed increase in labeling in deeper laminae (Williams et al., 1990). This pattern of Fos activation produced by noxious peripheral stimulation is not present in capsaicin-treated animals. CFA induces in these animals small, transient changes in Fos activation that neither persist nor have a typical time course.

Fos and Jun are thought to bind at AP-1 sites in the promoter region of target genes and thereby regulate transcription. Protooncogenes such as c-fos have been proposed to play important roles in the ability of neurons to convert a short-term stimulus into complex, long-term responses such as those involved in memory or neuronal plasticity (Goelet et al., 1986). The persistent changes in spinal cord excitability induced by peripheral tissue injury or stimulation of small-diameter afferents (Hylden et al., 1989; Woolf, 1989; Dubner, 1991) may be related to such mechanisms. Increased activation of small-diameter primary afferents results in expansion of the receptive fields of spinal dorsal horn nociceptive neurons and an increase in their excitability. These changes lead to enhancement of nociceptive activity at supraspinal sites that may be perceived as an increase in pain (Dubner, 1991; Hylden et al., 1991). Thus, the regulation of gene transcription by the protein products of proto-oncogenes 

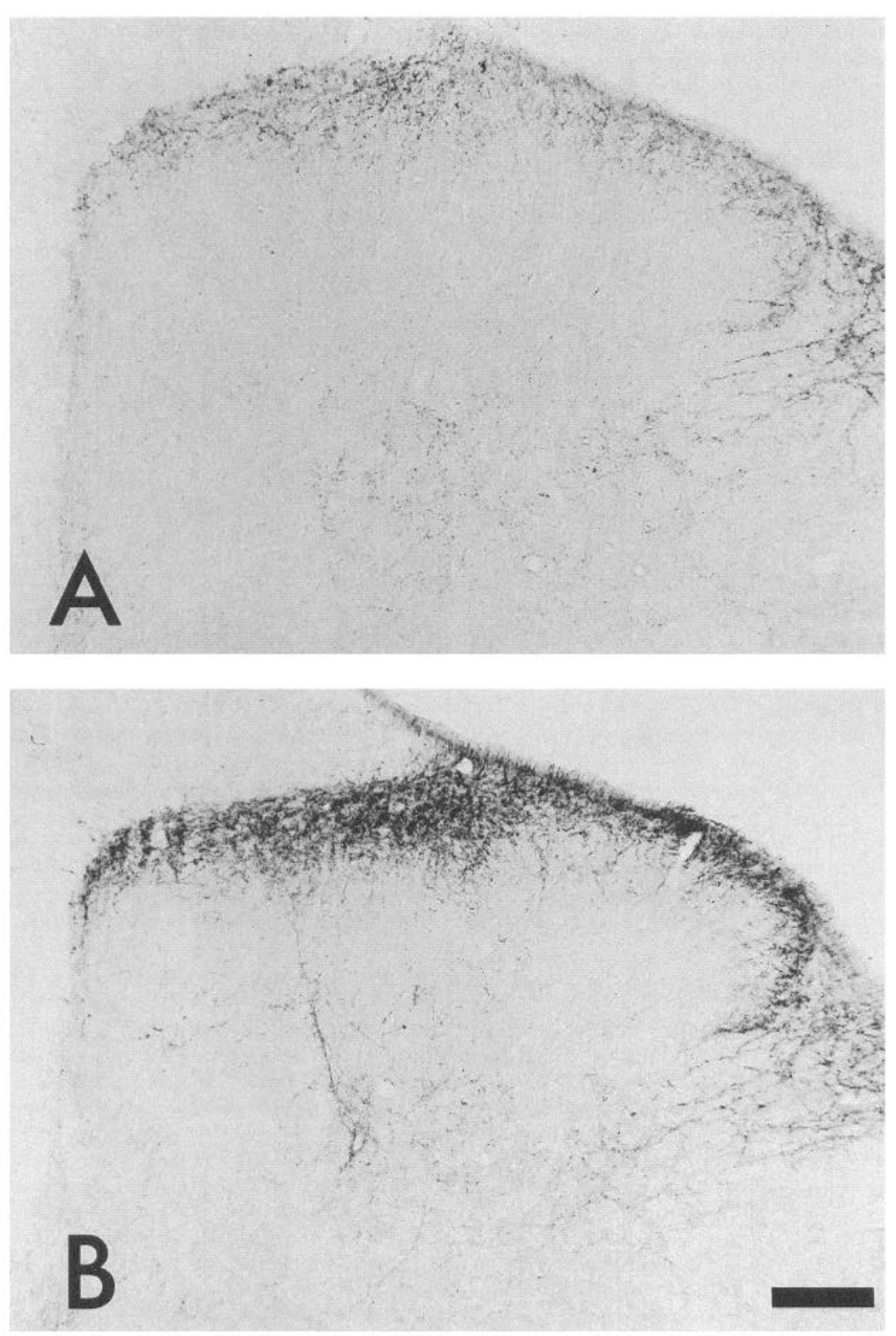

Figure 9. Photomicrographs of tissue sections from the lumbar spinal cord of a capsaicin-treated rat $(A)$ and a control $\operatorname{rat}(B)$. These $24 \mu \mathrm{m}$ transverse sections were immunocytochemically stained for SP. Neonatal capsaicin-treated rats exhibited a substantial depletion of SPlike immunoreactivity in the dorsal horn. Scale bar, $100 \mu \mathrm{m}$. such as c-fos may lead to long-term changes in spinal cord excitability and resulting persistent pain and hyperalgesia.

Peripheral tissue inflammation has also been shown to produce a robust increase in dynorphin peptide in the spinal cord (Iadarola et al., 1988a; Millan et al., 1988; Ruda et al., 1988). This increase is preceded by an increase in the levels of PPD mRNA coding for this opioid peptide product (Iadarola et al., 1988a). The role of dynorphin in the spinal cord processing of nociceptive stimuli is not clear. Dynorphin has been shown to have mixed effects on the excitability of dorsal horn neurons (Knox and Dickenson, 1987) and may contribute to the enhanced excitability of superficial dorsal horn neurons during conditions of peripheral inflammation (Hylden et al., 1991). Our present findings that the inflammation-induced increase in dynorphin gene expression is markedly attenuated by neonatal capsaicin treatment suggest that this upregulation is dependent on activity in capsaicin-sensitive primary afferents. Since neurons in the superficial dorsal horn exhibited expanded receptive fields and increased responsiveness to mechanical and thermal stimulation during peripheral inflammation (Hylden et al., 1989), it would be of interest to determine if the attenuating effect of capsaicin treatment on inflammation-induced increases in dynorphin has a comparable effect on the physiological responsiveness of dorsal horn neurons.

In the spinal dorsal horn, the stimulus-induced upregulation of Fos-LI is correlated with an increase in the expression of PPD mRNA and PPE mRNA. Previous studies have shown that c-fos mRNA increases within $30 \mathrm{~min}$ following injection of an inflammatory agent and precedes increased PPD mRNA expression that is first observed at $4 \mathrm{hr}$ (Draisci and Iadarola, 1989). Whereas unilateral inflammation has been shown to produce a robust increase in dynorphin gene expression (Iadarola et al., 1988a,b; Ruda et al., 1988; Draisci and Iadarola, 1989; Noguchi et al., 1991), relatively small increases in PPE mRNA were seen with RNA blot hybridization (Iadarola et al., 1988b; Draisci and Iadarola, 1989) and in situ hybridization (Noguchi et al., 
1992). Both PPD mRNA and PPE mRNA have been shown to increase within some spinal dorsal horn neurons that also exhibit increases in Fos-LI after inflammation (Noguchi et al., 1991, 1992). The majority (>80\%) of PPD mRNA- and PPE mRNA-positive neurons were also labeled for Fos-LI in their nuclei. This colocalization suggests that Fos plays a role in the regulation of opioid gene transcription. Our present findings that Fos-LI and PPD mRNA are attenuated in a similar fashion in capsaicin-treated rats provide further support to the hypothesis that these alterations in Fos activation and dynorphin gene expression are related events. Recently, an AP-1 like binding site in the promoter region of the rat prodynorphin gene has been shown to bind Fos and Jun proteins and to induce dynorphin gene transcription (Naranjo et al., 1991).

Our data suggest that a lack of Fos activation does not necessarily imply a lack of neuronal activation. Capsaicin-treated rats had an attenuated response in terms of the number of neurons exhibiting Fos-LI, but these same capsaicin-trcated rats did respond to noxious thermal stimuli and did develop thermal hyperalgesia. Thus, the small number of unmyelinated primary afferents remaining after neonatal capsaicin treatment may be sufficient for the behavioral response to inflammation. At the same time, this reduced number of afferents may only be capable of producing Fos activation in a restricted population of spinal cord neurons. The data suggest that activity in unmyelinated primary afferents is critical for the full expression of Fos activity in response to peripheral nociceptive inputs. The concomitant loss of many peptide-containing primary afferents following capsaicin treatment suggests that neuropeptides such as SP and calcitonin gene-related peptide participate in the initiation of synaptic events that lead to Fos and dynorphin gene activation.

In this study, we have seen that a selective destruction of small-diameter, mainly unmyelinated primary afferents can be a useful tool in examining the relationships between molecular, biochemical, and behavioral events that are relevant to spinal cord function. Our observations support a role for small-diameter unmeylinated primary afferents in the stimulus-induced upregulation of both Fos-LI and PPD mRNA. The attenuation of inflammation-induced increases in Fos-LI and PPD mRNA by neonatal capsaicin treatment provides further support for the role of Fos in dynorphin gene transcription in the spinal cord. These observations have important implications in our understanding of mechanisms of stimulus-dependent plasticity in the spinal cord.

\section{References}

Buck SH, Burks TF (1986) The neuropharmacology of capsaicin. Pharmacol Rev 38:179-226.

Bullitt E (1989) Induction of c-fos-like protein within the lumbar spinal cord and thalamus of the rat following peripheral stimulation. Brain Res 493:391-397.

Bullitt E (1990) Expression of c-fos-like protein as a marker for neuronal activity following stimulation in the rat. J Comp Neurol 296: 517-530

Cervero F, Shouenborg J, Sjölund BH, Waddell P (1984) Cutaneous inputs to dorsal horn neurones in adult rats treated at birth with capsaicin. Brain Res 301:47-57.

Civelli O, Douglass J, Goldstein A, Herbert E (1985) Scquence and expression of the rat prodynorphin gene. Proc Natl Acad Sci USA $82: 4291-4295$.

Curran T, Morgan JI (1987) Memories of fos. Bioessays 7:255-258.

Doucette R, Theriault E, Diamond J (1987) Regionally selective elimination of cutaneous thermal nociception in rats by neonatal capsaicin. J Comp Neurol 261:583-591.
Draisci G, Iadarola MJ (1989) Temporal analysis of increases in c-fos, preprodynorphin and preproenkephalin mRNAs in rat spinal cord. Mol Brain Res 6:31-37.

Dubner R (1991) Neuronal plasticity and pain following peripheral tissue inflammation or nerve injury. In: Proceedings of the VIth world congress on pain (Bond M, ed), pp 263-276. Amsterdam: Elsevier.

Gamse R, Holzer P, Lembeck F (1980) Decrease of substance P in primary afferent neurones and impairment of neurogenic plasma extravasation by capsaicin. Br J Pharmacol 68:207-213.

Goclet P, Castellucci VF, Schacher S, Kandel ER (1986) The long and short of long-term memory-a molecular framework. Nature 322: 419-422.

Hammond DL, Ruda MA (1989) Developmental alterations in thermal nociceptive threshold and the distribution of immunoreactive calcitonin gene-related peptide and substance $P$ after neonatal administration of capsaicin in the rat. Neurosci Lett 97:57-62.

Hammond DL, Ruda MA (1991) Developmental alterations in the distribution of immunoreactive calcitonin gene-related peptide, substance $P$ and fluoride-resistant acid phosphatase in the spinal cord of the rat after neonatal administration of capsaicin: relationship to nociceptive threshold. J Comp Neurol 312:436-450.

Hargreaves K, Dubner R, Brown F, Flores C, Joris J (1988) A new and sensitive method for measuring thermal nociception in cutaneous hyperalgesia. Pain 32:77-88.

Hunt SP, Pini A, Evan G (1987) Induction of c-fos-like proteins in spinal cord neurons following sensory stimulation. Nature 328:632634.

Hylden JLK, Nahin RL, Traub RJ, Dubner R (1989) Expansion of receptive fields of spinal lamina I projection neurons in rats with unilateral adjuvant-induced inflammation: the contribution of dorsal horn mechanisms. Pain 37:229-243.

Hylden JLK, Nahin RL, Traub RJ, Dubner R (1991) Effects of spinal kappa-opioid receptor agonists on the responsiveness of nociceptive superficial dorsal horn neurons. Pain 44:187-193.

Iadarola MJ, Brady LS, Draisci G, Dubner R (1988a) Enhancement of dynorphin gene expression in spinal cord following experimental inflammation: stimulus specificity, behavioral parameters and opioid receptor binding. Pain 35:313-326.

Iadarola MJ, Douglass J, Civelli O, Naranjo JR (1988b) Differential activation of spinal cord dynorphin and enkephalin neurons during hyperalgesia: evidence using cDNA hybridization. Brain Res 455: 205-212.

Iadarola MJ, Yeung CL, Draisci G, Ruda MA (1989) Prolonged elevation of multuiple Fos immunoreactive proteins in rat spinal cord: western blot and immunocytochemical analysis. Soc Neurosci Abstr 15:468.

Jancso G, Kiraly E, Jancso-Gabor A (1977) Pharmacologically induced selective degeneration of chemosensitive primary sensory neurons. Nature 270:741-743.

Kashiba H, Senba E, Ueda Y, Tohyama M (1990) Relative sparing of calcitonin gene-related peptide-containing sensory neurons following neonatal capsaicin treatment in the rat. Peptides 11:491-496.

Knox RJ, Dickenson AH (1987) Effects of selective and non-selective $\kappa$-opioid receptor agonists on cutaneous $C$-fibre-evoked responses of rat dorsal horn neurones. Brain Res 415:21-29.

Lynn B, Shakhanbeh J (1988) Properties of A $\delta$ high threshold mechanoreceptors in the rat hairy and glabrous skin and their response to heat. Neurosci Lett 85:71-76.

Menétrey D, Gannon A, Levine JD, Basbaum AI (1989) Expression of c-fos protein in interneurons and projection neurons of the rat spinal cord in response to noxious somatic, articular and visceral stimulation. J Comp Neurol 285:177-195.

Millan MJ, Członkowski A, Morris B, Stein C, Arendt R, Huber A, Hollt V, Herz A (1988) Inflammation of the hind limb as a model of unilateral, localized pain: influence on multiple opioid systems in the spinal cord of the rat. Pain 35:299-312.

Morgan JI, Curran T (1989) Stimulus-transcription coupling in neurons: role of cellular immediate-early genes. Trends Neurosci 12:459462.

Nagy JI, Hunt SP (1983) The termination of primary afferents within the rat dorsal horn: evidence for rearrangement following capsaicin treatment. J Comp Neurol 218:145-158.

Nagy JI, Hunt SP, Iversen LL, Emson PC (1981) Biochemical and anatomical obscrvations on the degeneration of peptide-containing primary afferent neurons after neonatal capsaicin. Neuroscience 6: 1923-1934. 
Naranjo JR, Mellström B, Achaval M, Sassone-Corsi P (1991) Molecular pathways of pain: fos/jun-mediated activation of a noncanonical AP-1 site in the prodynorphin gene. Neuron 6:607-617.

Noguchi K, Morita Y, Kiyama H, Sato M, Ono K. Tohyama M (1989) Preproenkephalin gene expression in the rat spinal cord after noxious stimuli. Mol Brain Res 5:227-234.

Noguchi K, Kowalski K, Traub R, Solodkin A, ladarola MJ, Ruda MA (1991) Dynorphin expression and Fos-like immunoreactivity following inflammation induced hyperalgesia are colocalized in spinal cord neurons. Mol Brain Res 10:227-233.

Noguchi K. Dubner R, Ruda MA (1992) Preproenkephalin mRNA in spinal dorsal horn neurons is induced by peripheral inflammation and is colocalized with Fos and Fos-related proteins. Neuroscience 46:561-570.

Presley RW, Menétrey D, Levine JD, Basbaum AI (1990) Systemic morphine suppresses noxious stimulus-evoked fos protein-like immunoreactivity in the rat spinal cord. J Neurosci 10:323-335.

Réthelyi M, Salim MZ, Jansco G (1986) Altered distribution of dorsal root fibers in the rat following neonatal capsaicin treatment. Neuroscience 18:749-761.

Ruda MA, Coffield J, Steinbusch HWM (1982) Immunocytochemical analysis of serotonergic axons in laminae I and II of the lumbar spinal cord of the cat. J Neurosci 2:1660-1671.

Ruda MA, Bennett GJ, Dubner R (1986) Neurochemistry and neural circuitry in the dorsal horn. Prog Brain Res 66:219-268.

Ruda MA, Iadarola MJ, Cohen LV, Young WS III (1988) In situ hybridization histochemistry and immunocytochemistry reveal an increase in spinal dynorphin biosynthesis in a rat model of peripheral inflammation and hyperalgesia. Proc Natl Acad Sci USA 85:622-626.

Saporta $S$ (1986) Loss of spinothalamic tract neurons following neonatal treatment of rats with the neurotoxin capsaicin. Somatosens Res 4:153-173

Sheng M, Greenberg ME (1990) The regulation and function of c-fos and other immediate early genes in the nervous system. Neuron 4: $477-485$.
Skofitsch G, Jacobowitz DM (1985) Quantitative distribution of calcitonin gene-related peptide in the rat central nervous system. Peptides 6:1069-1073.

Solodkin A, Ruda MA (1988) Effects of capsaicin on spinal cord axons that colocalize substance $P$ and calcitonin gene-related peptide. Soc Neurosci Abstr 14:694.

Sternberger LA (1979) Immunocytochemistry, 2d ed. New York: Wiley.

Tolle TR, Castro-Lopes JM, Coimbra A, Zieglgansberger W (1990) Opiates modify induction of c-fos proto-oncogene in the spinal cord of the rat following noxious stimulation. Neurosci Lett 111:46-51.

Wall PD, Fitzgerald M, Nussbaumer JC, Van der Loos H, Devor M (1982) Somatotopic maps are disonganized in adult rodents treated neonatally with capsaicin. Nature 25:691-693.

Williams S, Evan GI, Hunt SP (1990) Changing patterns of c-fos induction in spinal neurons following thermal cutaneous stimulation in the rat. Neuroscience 36:73-81.

Wisden W, Errington ML. Williams S, Dunnett SB, Waters C, Hitchcock D, Evan G, Bliss TVP, Hunt SP (1990) Differential expression of immediate early genes in the hippocampus and spinal cord. Neuron $4: 603-614$

Woolf CJ (1989) Afferent induced alterations of receptive field propertics. In: Processing of sensory information in the superficial dorsal horn of the spinal cord (Cervero F, Bennett GJ, Headley PM, eds), pp 443-462. New York: Plenum.

Yoshikawa K, Williams C, Sabol SL (1984) Rat brain preproenkephalin mRNA: cDNA cloning, primary structure, and distribution in the nervous system. J Biol Chem 259:14301-14308.

Young WS III, Bonner TI, Brann M (1986) Mesencephalic dopamine neurons regulate the expression of neuropeptide $m R N A s$ in the rat forebrain. Proc Natl Acad Sci USA 83:9827-9831.

Zimmermann $M$ (1983) Ethical guidelines for investigations of experimental pain in conscious animals. Pain 16:109-110. 